Н.М. Шириналиев

\title{
Осложнения гестационного периода у больных раком шейки матки
}

Беларусь наравне с государствами Восточной Европы входит в группу стран с высоким уровнем заболеваемости раком шейки матки. В последнее время отмечают рост частоты возникновения данной патологии среди беременных. Результаты исследования показывают, что рак шейки матки в анамнезе, как и выявленный в период беременности, не является показанием к прерыванию беременности. Оценка течения и исходов беременности у женщин со злокачественными новообразованиями шейки матки показала, что больные раком шейки матки способны к рождению ребенка с нормальной массой тела и средним уровнем баллов по шкале Апгар.

Ключевые слова: гестационный период, беременность, рак шейки матки.

\section{Введение}

Беларусь наравне с Польшей, Украиной, Россией и прибалтийскими государствами относится к странам с высоким уровнем заболеваемости раком шейки матки (РШМ) (Аксель Е.М., 2012). В последнее время отмечается возрастание частоты возникновения указанной патологии среди женщин фертильного возраста, что наряду с тенденцией к пролонгации возраста наступления беременности является фактором увеличения числа беременных с РШМ (Ульрих Е.А. и соавт., 2014). По данным литературы, на 10 тыс. беременных приходится до 15 случаев заболевания (Урманчеева А.Ф., 2009). В странах СНГ большинство врачей предлагает прервать беременность не только при верификации РШМ, но и при выявлении в мазках аномалий любой степени (Голицына Ю.С. и соавт., 2018). Однако является ли выявление неоплазии в слизистой оболочке шейки матки в период гестации показанием для искусственного прерывания беременности?

Цель - оценить акушерские и перинатальные исходы у беременных с РШМ в анамнезе, а также выявленным в период гестации, сравнив их с таковыми беременных без РШМ.

\section{Объект и методы исследования}

На базе отделений патологии беременности № 1 и № 2 ГУ «Республиканский научно-практический центр «Мать и дитя» и ГУ «Республиканский научно-практический центр онкологии и медицинской радиологии имени Н.Н. Александрова» (Минск, Республика Беларусь) проведено исследование с участием 88 беременных в возрасте 18-40 лет. Большинство женщин - повторнородящие.

Всем участницам проводили комплексное обследование с минимизацией тератогенного воздействия на плод. Клиническая часть диагностики включала:

- выявление жалоб путем устного опроса;

- сбор акушерского, гинекологического, общетерапевтическо-

го, наследственного и аллергологического анамнеза

- физикальный осмотр;

- лабораторную диагностику основных показателей крови.

Пациенткам проводили гистологическое исследование биопсийного материала, кольпоскопию, тест на вирус папилломы человека, ультразвуковое исследование органов малого таза, компьютерную томографию (с применением защитных экранов) и магнитно-резонансную томографию, с помощью которых устанавливали заключительный клинический диагноз с учетом шифра РШМ по системе TNM.

Посредством общеклинических и специальных методов диагностики проводили: оценку частоты основных осложнений гестационного периода, мониторинг аномалий родовой деятельности, анализ перинатальных исходов и морфогистологическое исследование последов.

Оценку состояния новорожденных проводили по шкале Апгар также анализировали антропометрические данные новорожденных.

В 1-ю группу ( $\mathrm{n}=11$, средний возраст - 30 лет) включили беременных, у которых РШМ выявлен после зачатия. С помощью общеклинических и специальных методов диагностики в 64\% случаев верификация диагноза стала возможной во II триместр беременности на сроке гестации 14-26-я неделя, в $27 \%$ - в III и лишь в $9 \%$ - в I триместр.

Во 2-ю группу ( $\mathrm{n}=33$, средний возраст -32 года) включили беременных с РШМ в анамнезе. У большинства пациенток от момента верификации диагноза и терапии до наступления беременности прошло $>3$ лет.

В 3-ю группу ( $n=44$, средний возраст -29 лет) составили беременные с физиологическим течением беременности без диагностированного РШМ. В эту группу не включали пациенток с сопутствующей острой и хронической гинекологической и экстрагенитальной патологией.

\section{Результаты и их обсуждение}

РШМ, выявленный после зачатия (1-я группа), не осложнял течение беременности в 46\% случаев. Среди осложнений лидировала хроническая фетоплацентарная недостаточность (72\%), у $19 \%$ женщин отмечена угроза прерывания беременности, хроническая внутриутробная гипоксия плода и многоводие, у 9\% анемия и гестоз.

Обострений хронических заболеваний у пациенток 1-й группы не выявлено. Среди сопутствующих патологий преобладали акушерско-гинекологические заболевания - эрозия шейки матки, эрозивный эктропион, дисплазия шейки матки, хламидиоз. Среди экстрагенитальной патологии в этой группе выявлены гидронефроз, миопия слабой степени, язва желудка и двенадцатиперстной кишки. У 9\% пациенток коморбидных заболеваний не отмечено.

Согласно данным исследования, в 64\% случаев онкологический процесс в шейке матки не влиял на срочность родоразрешения, которое наступало на сроке 37-39-й недели. Преждевременные роды на сроке гестации 32-й недели в данной группе наступали у $36 \%$ женщин. У $50 \%$ преждевременно родивших женщин выявлен РШМ III стадии. План ведения родов в $100 \%$ случаев предопределен по варианту оперативного родоразрешения с целью предотвращения попадания опухолевых клеток в кровоток ввиду возможного разрыва шейки матки. Послеоперационных осложнений у пациенток 1-й группы не отмечено.

У $30 \%$ пациенток 2-й группы РШМ не отягощал течение беременности, у $51 \%$ диагностирована угроза прерывания беременности. Обострений хронических заболеваний у беременных 2-й группы не отмечено. Среди сопутствующих заболеваний лидировала акушерско-гинекологическая патология - 49\% случаев (эрозия шейки матки, эктропион, дисплазия, хламидиоз, уреаплазмоз), патология щитовидной железы (21\%), других органов (15\%). У 15\% пациенток сопутствующей патологии не отмечено.

Согласно результатам лабораторных исследований, уровень гемоглобина в среднем в группе составлял 100,0 49,2 г/л, ско-

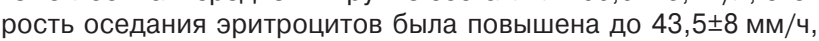
также отмечено повышение содержания палочкоядерных нейтро- 
филов и лейкоцитов, снижение показателей активированного частичного тромбопластинового времени и протромбинового времени, незначительное повышение фибриногена.

У большинства женщин 2-й группы роды были срочными, в срок 37-39-й недели; преждевременные роды (28-32-я неделя гестации) наступили в $15 \%$ случаев. Родоразрешение проведено путем кесарева сечения в $100 \%$ случаев в связи с рубцовой деформацией шейки матки после оперативного лечения неопластического процесса.

Таким образом, терапия злокачественного новообразования шейки матки (в том числе оперативное вмешательство) у женщин сохраняет возможность естественного зачатия и благоприятного перинатального исхода без применения кумулятивных репродуктивных технологий. Причем, согласно данным литературы, наличие онкологического процесса в других органах репродуктивной системы женщины в анамнезе также сохраняет фертильность (Goldrat O. et al., 2015).

Среди осложнений беременности в 3-й группе преобладала хроническая фетоплацентарная недостаточность. Реже отмечали угрозу прерывания беременности, хроническую внутриутробную гипоксию плода, кольпит, анемию, истмикоцервикальную недостаточность, преждевременное излитие околоплодных вод, гестационный гипотиреоз, ножное предлежание плода. У $41 \%$ женщин патологии беременности не отмечено. Общетерапевтическое обследование беременных 3-й группы не выявило обострения хронических заболеваний. Среди сопутствующих патологий отмечены кардиологические заболевания, заболевания желудочно-кишечного тракта, щитовидной железы, миопия и др. У $30 \%$ женщин коморбидной патологии не выявлено. Лабораторные показатели в 3-й группе - в пределах нормы. У всех обследуемых 3-й группы роды наступили в срок $>260$ дней. Родоразрешение проводили оперативным путем в 100\% случаев. Показанием к кесареву сечению была слабость родовой деятельности.

В 8/8-8/9 баллов по шкале Апгар оценено состояние $64 \%$ новорожденных в 1-й, 85\% - 2-й и 100\% - 3-й группе. Преждевременно рожденные дети нуждались в проведении искусственной вентиляции легких. Средняя масса новорожденных в группах составила 2500; 3042 и 3046 г, средний рост - 44; 49 и 52 см соответственно.

\section{Заключение}

У женщин репродуктивного возраста, которым установлен диагноз РШМ либо в период беременности, либо до ее наступления, сохраняется фертильность. Выявленный в период беременности РШМ, также как и РШМ в анамнезе, не является препятствием для вынашивания плода до срока 37-39-й недели и рождения жизнеспособного ребенка, не имеющего при первичной оценке каких-либо значимых отклонений от нормы.

Анализ осложнений беременности показал, что РШМ, выявленный в период беременности, не осложняет течения периода гестации в 36\%, а при выявлении до беременности - в 30\% случаях. Также установлено, что в группе женщин, у которых РШМ выявлен до наступления беременности, в 3 раза чаще, чем у беременных с РШМ, выявленным во время гестации, определялась угроза прерывания беременности - 52 и 18\% соответственно. Вероятно, это объясняется тем, что в анамнезе у женщин 2-й группы присутствовал один из вариантов оперативного лечения.

У всех пациенток с РШМ, независимо от анамнестических данных о верификации диагноза, родоразрешение проводили путем кесарева сечения, что свидетельствует о сопоставимости пациенток исследуемых групп при определении тактики ведения родов.

\section{Практические рекомендации}

1. Акушерам-гинекологам женской консультации рекомендовано проводить беседы с беременными, у которых выявлен РШМ в период беременности или в анамнезе, о возможности благоприятного исхода беременности.
2. Рекомендовано привлечение психологических служб, осуществляющих работу с беременными на разных уровнях здравоохранения, с целью обеспечения благоприятного психоэмоционального фона беременных, у которых выявлен РШМ.

3. Пропаганда возможности вынашивания беременности для первородящих, у которых выявлен РШМ в период беременности или до ее наступления, в том числе путем организации соответствующих электронных ресурсов и привлечения женщин, завершивших беременность, протекавшую на фоне РШМ, с благоприятным исходом и имеющих здоровых детей.

4. Терапевтические мероприятия, необходимые для лечения пациенток с РШМ, должны быть направлены также на протекцию фертильности, поскольку наличие опухолевого процесса и интервенционные вмешательства на шейке матки могут приводить к изменению гормонального фона.

5. Родоразрешение пациенток с РШМ рекомендовано производить путем кесарева сечения, независимо от срока давности верификации РШМ.

\section{Список использованной литературы}

Аксель Е.М. (2012) Статистика злокачественных новообразований женской половой сферы. Онкогинекология, 1: 18-25.

Голицына Ю.С., Шмаков Р.Г., Хабас Г.Н., Оводенко Д.Л. (2018) Рак шейки матки и беременность: основные принципы диагностики, лечения и ведения беременности. Доктор.Ру, 2(146): 15-19.

Ульрих Е.А., Вербитская Е.А., Урманчеева А.Ф., Кутушева Г.Ф. (2014) Тактика ведения беременности при преинвазивном раке шейки матки. Фарматека, 4(277): 68-70.

Урманчеева А.Ф. (2009) Гинекологический рак в сочетании с беременностью. Практ. онкол., 10(4): 184-197.

Goldrat O., Kroman N., Peccatori F.A. et al. (2015) Pregnancy following breast cancer using assisted reproduction and its effect on long-term outcome. Eur. J. Cancer, 51(12): 1490-1496.

\section{Ускладнення гестаційного періоду у хворих на рак шийки матки \\ Н.М. Ширіналіє}

Резюме. Білорусь нарівні з державами Східної Європи входить до групи країн із високим рівнем захворюваності на рак шийки матки. Останнім часом відзначають зростання частоти виникнення цієі патології серед вагітних. Результати цього дослідження доводять, що рак шийки матки в анамнезі, як і виявлений у період вагітності, не $\epsilon$ показанням до переривання вагітності. Оцінка перебігута результатів вагітності у жінок зі злоякісними новоутвореннями шийки матки показала, що хворі на рак шийки матки здатні до народження дитини з нормальною масою тіла і середнім рівнем за шкалою Апгар.

Ключові слова: гестаційний період, вагітність, рак шийки матки.

\section{Complications of gestational period in women with cervical cancer}

\section{N.M. Shirinaliyev}

Summary. Belarus, along with Eastern European countries, is included in the group of countries with a high incidence of cervical cancer. Recently, there has been an increase in the incidence of this pathology among pregnant women. The results of this study prove that cervical cancer verified in history, as well as cervical cancer detected during pregnancy, is not an indication for abortion. An assessment of the course and outcomes of pregnancy in women with malignant neoplasms of the cervix uteri showed that these women are capable of giving birth to a child with normal body weight and an average level on the Apgar scale.

Key words: gestational period, pregnancy, cervical cancer.

\section{Адрес для переписки:}

Шириналиев Наиль Машдиевич

220013, Республика Беларусь, Минск, ул. П. Бровки, 3, корп. 3

Государственное учреждение образования «Белорусская медицинская академия последипломного образования»

E-mail: shirinaliyev-nail@rambler.ru

Получено 11.06 .2020 